\section{Pure Red Cell Aplasia Developing after Treatment of Pleural Recurrence of Thymoma, Successfully Treated with Cyclosporin A but not with Tacrolimus}

Kazuhiro Fukushima, Toshio Sato, Shigeaki Mitsuhashi, Takahisa Gono, Kazuma Kaneko, Masahide Yazaki, Masayuki Mastuda and Shu-ichi Ikeda

Key words: cyclosporin A, myasthenia gravis, pure red cell aplasia, tacrolimus, thymoma

(DOI: 10.2169/internalmedicine.45.1587)

Pure red cell aplasia (PRCA) is an autoimmune disorder characterized clinically by a selective decrease in erythrocytes and their progenitors in the peripheral blood and bone marrow, respectively (1). This disease occurs occasionally as a complication of myasthenia gravis (MG) with or without thymoma, and immunosuppressive agents are usually employed for treatment in addition to blood transfusion (1-3). Here, we report a patient with PRCA developing after treatment of pleural recurrence of thymoma, treated successfully with cyclosporin A (CsA) but not tacrolimus.

A 33-year-old man underwent extended thymectomy followed by irradiation at a total dose of 40 Gy based on a diagnosis of generalized MG associated with invasive thymoma. Although MG symptoms disappeared completely under oral prednisolone treatment at $10 \mathrm{mg} /$ day, computed tomography (CT) demonstrated pleural recurrence of thymoma in the left thoracic cavity 4 months later. Two courses of ADOC (doxorubicin $40 \mathrm{mg} / \mathrm{m}^{2}$ and cisplatin $50 \mathrm{mg} / \mathrm{m}^{2}$ on day 1 , vincristine $0.6 \mathrm{mg} / \mathrm{m}^{2}$ on day 2 , and cyclophosphamide $700 \mathrm{mg} / \mathrm{m}^{2}$ on day 3; all repeated 3 weeks later) were ineffective, and eight months later the patient underwent cytoreductive surgery and intraoperative hyperthermic intrathoracic perfusion chemotherapy with cisplatin at 60 $\mathrm{mg} / \mathrm{m}^{2}$. One week after the operation, the patient suddenly complained of general fatigue with shortness of breath, and hematology showed severe anemia (red blood cells $255 \times 10^{4}$ / $\mu \mathrm{l}$; hemoglobin $7.1 \mathrm{~g} / \mathrm{dl}$; hematocrit $21.5 \%$ ) with a reduced percentage of reticulocytes $(0.2 \%)$ and normal levels of leukocytes $(7200 / \mu \mathrm{l})$ and platelets $\left(20.2 \times 10^{4} / \mu \mathrm{l}\right)$. Renal and hepatic indices were within the normal limits, and the patient was negative for antibodies against infectious agents, including parvovirus B19. Bone marrow aspirate demonstrated a selective absence of erythroid cells. Tacrolimus was started

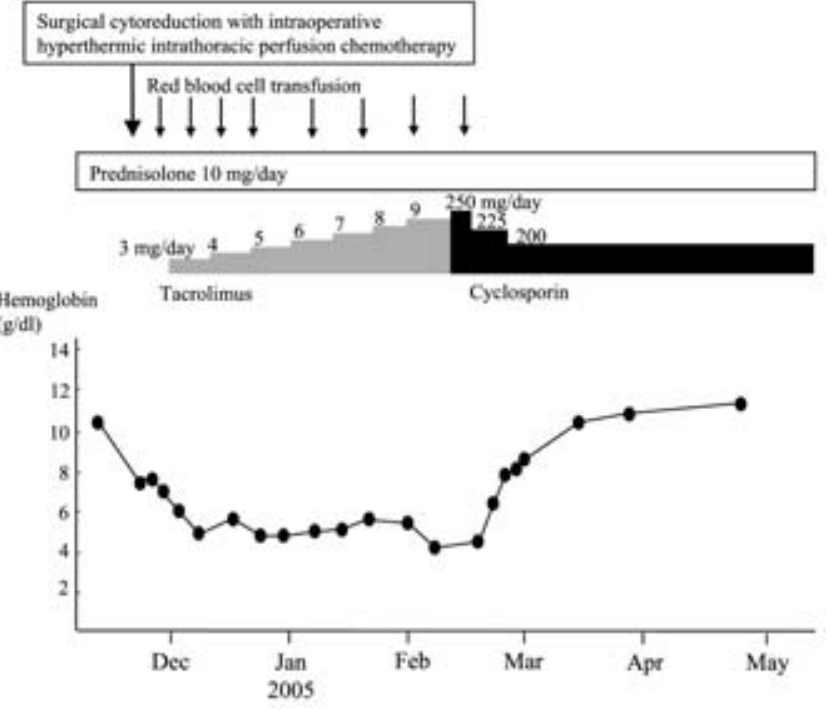

Figure 1. The patient's clinical course. Treatment of pure red cell aplasia with cyclosporin A was successful, but treatment with tacrolimus was not.

at $3 \mathrm{mg} /$ day in addition to blood transfusion and prednisolone, and gradually increased to $9 \mathrm{mg}$ /day while monitoring the plasma trough concentration (Fig. 1). Nevertheless, anemia did not improve, and approximately two months later CsA was employed at $250 \mathrm{mg} /$ day in place of tacrolimus. Reticulocytes appeared in the peripheral blood 2 weeks after starting CsA, and anemia improved gradually. The patient has since been in good general condition with no recurrence of thymoma on CT and almost normal levels of red blood cells and hemoglobin. There were no adverse effects ascribable to CsA with maintenance of the trough plasma concentration between 100 and $150 \mathrm{ng} / \mathrm{ml}$. MG was clinically stable throughout the clinical course of PRCA.

The present patient showed acute-onset severe anemia with selective absence of erythroid cells in the bone marrow, leading to a diagnosis of PRCA. Cisplatin had been administered in the thoracic cavity shortly before development of PRCA, but the involvement of this drug was excluded because anemia persisted without a tendency of recovery even without myelosuppressive agents. Immunological abnormalities ascribable to pleural recurrence of thymoma may have been central to the pathogenesis of PRCA in our patient as reported previously $(2,3)$. Several reports have indicated that in PRCA T lymphocytes play a key role in the production of autoantibodies directed to suppress erythropoiesis (1$3)$, and CsA has recently become accepted as the first-line drug for treatment of this disease in Japan $(4,5)$. Tacrolimus 
can also be used for treatment of PRCA because of the mechanism similar to CsA with selective suppression of the activation of $\mathrm{T}$ lymphocytes by acting as a calcineurin inhibitor (6), but our patient was successfully treated with the latter but not with the former. Although the precise reason is unclear, a difference in the intracytoplasmic binding protein between CsA and tacrolimus may be related to these therapeutic outcomes (7). Even if one of CsA and tacrolimus is ineffective for PRCA, the other should be actively considered as the next therapeutic option, because the clinical efficacy of these drugs may depend on the interaction with their binding proteins which may be variable in each individual.

\section{References}

1. Kwong YL, Wong KF, Liang RH, Chu YC, Chan LC, Chan TK. Pure red cell aplasia: clinical features and treatment results in 16 cases. Ann Hematol 72: 137-140, 1996.

2. Murakawa T, Nakajima J, Sato H, Tanaka M, Takamoto S, Fukayama M. Thymoma associated with pure red-cell aplasia: clinical features and prognosis. Asian Cardiovasc Thorac Ann 10: 150154, 2002.

3. Suto Y, Araga S, Sakuma K, Nakano T, Ishiga K, Tajima F, Kowa $\mathrm{H}$, Nakashima K. Myasthenia gravis with thymus hyperplasia and pure red cell aplasia. J Neurol Sci 224: 93-95, 2004.

4. Omine M. Reference guide for treatment of pure red cell aplasia.
Intractable Disease Division, the Ministry of Public Health, Labor and Welfare, Japan, 2005 (in Japanese).

5. Mamiya S, Itoh T, Miura AB. Acquired pure red cell aplasia in Japan. Eur J Haematol 59: 199-205, 1997.

6. Yoshida S, Konishi T, Nishizawa T, Yoshida Y. Effect of tacrolimus in a patient with pure red-cell aplasia. Clin Lab Haematol 27: 67-69, 2005.

7. Ho S, Clipstone N, Timmermann L, et al. The mechanism of action of cyclosporin A and FK506. Clin Immunol Immunopathol 80: S40-S45, 1996.

(C) 2006 The Japanese Society of Internal Medicine http://www.naika.or.jp/imindex.html 